\title{
Comparison of dust released from sanding conventional and nanoparticle-doped wall and wood coatings
}

\author{
ISMO KALEVI KOPONEN ${ }^{\mathrm{a}}$, KELD ALSTRUP JENSEN ${ }^{\mathrm{a}}$ AND THOMAS SCHNEIDER $^{\mathrm{b}}$

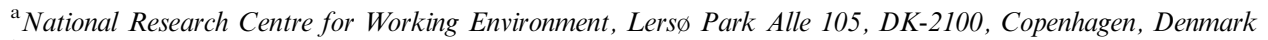 \\ ${ }^{\mathrm{b}}$ Køgemestervej 13, DK 3400, Hillerød, Denmark
}

\begin{abstract}
Introduction of engineered nanoparticles (ENPs) into traditional surface coatings (e.g., paints, lacquers, fillers) may result in new exposures to both workers and consumers and possibly also a new risk to their health. During finishing and renovation, such products may also be a substantial source of exposure to ENPs or aggregates thereof. This study investigates the particle size distributions $(5.6 \mathrm{~nm}-19.8 \mu \mathrm{m})$ and the total number of dust particles generated during sanding of ENP-doped paints, lacquers, and fillers as compared to their conventional counterparts. In all products, the dust emissions from sanding were found to consist of five size modes: three modes under $1 \mu \mathrm{m}$ and two modes around 1 and $2 \mu \mathrm{m}$. Corrected for the emission from the sanding machine, the sanding dust, was dominated by $100-300 \mathrm{~nm}$ size particles, whereas the mass and surface area spectra were dominated by the micrometer modes. Adding ENPs to the studied products only vaguely affected the geometric mean diameters of the particle modes in the sanding dust when compared to their reference products. However, we observed considerable differences in the number concentrations in the different size modes, but still without revealing a clear effect of ENPs on dust emissions from sanding.
\end{abstract}

Journal of Exposure Science and Environmental Epidemiology (2011) 21, 408-418; doi:10.1038/jes.2010.32; published online 19 May 2010

Keywords: nanomaterial, nanotechnology, occupational health, aerosol size distributions.

\section{Introduction}

Engineered nanoparticles (ENPs), also called particulate nanomaterials and nano-objects, are defined to be industrially produced entities, which generally are smaller than $100 \mathrm{~nm}$ along at least one physical axis. Application of ENPs provides vast opportunities to improve the properties of existing industrial products or the development of new products with new properties. The paint and lacquer manufacturers already use ENPs in some of their most recent commercial products. The aim is to obtain improved or special paint properties, such as water repellence, scratch resistance, improved durability, and antibacterial properties. Consequently, the paint and lacquer industry may become one of the largest users of ENPs in the near future, and numerous people may potentially become exposed to ENPs during production and application of these products as well as during subsequent finishing and renovation.

The uncertainty about the exposure characteristics and the potential hazard of dust generated from sanding ENP-doped

1. Address all correspondence to: Dr. Ismo Kalevi Koponen, National Research Centre for Working Environment, Lers $\varnothing$ Park Alle 105, Copenhagen, DK 2100, Denmark.

Tel: +453916 5312. Fax: +4539165201.

E-mail: ikk@nrcwe.dk

Received 7 January 2010; accepted 12 April 2010; published online 19 May 2010 paints and lacquers as compared to that of conventional products are among the most important obstacles for the successful introduction of these new products. Some toxicological studies have shown that certain low-soluble ENPs (e.g., $\mathrm{TiO}_{2}$, silica, carbon black, latex particles), which also are used in paints, have a greater toxicity than larger particles of the same compound (Donaldson et al., 2000). Other studies have shown a more complex picture with sometimes opposite relations (Warheit et al., 2006). It is likely that the physicochemical properties of the ENPs and the exposure characteristics have an equally important role (Rossi et al., 2010). Therefore, it is of crucial importance to obtain a detailed understanding of the exposure characteristics during production and handling of powder ENPs, but also during reworking ENP-doped materials, which is the topic of this paper.

In the past few years, numerous studies have investigated and discussed the potential health risks of nanomaterials (Oberdorster et al., 1995; Balbus et al., 2006; Wallace et al., 2006; Oberdorster et al., 2007). Fewer studies have studied or assessed the exposure risks during handling ENPs (Maynard et al., 2004; Jensen et al., 2009; Brouwer et al., 2009). To the best of our knowledge, there are no studies characterizing the potential exposure to nanoparticles from sanding nanoparticle-doped paints and lacquers. A few studies have characterized the exposure to dust from sanding conventional materials in the field as well as in the laboratory.

Scholz et al. (2002) studied 11 job sites to assess the exposure to dust and lead $(\mathrm{Pb})$ from sanding $\mathrm{Pb}$-bearing 
paint. Total dust was sampled in the breathing zone using closed face filter cassettes. Thirty-minute total dust exposures were $1.6(\mathrm{std}=2), 6.7(\mathrm{std}=3.6)$, and $14(\mathrm{std}=13) \mathrm{mg} / \mathrm{m}^{3}$ for HEPA exhausted power sanding, manual dry sanding, and uncontrolled power sanding, respectively. The $\mathrm{Pb}$ content in the airborne dust was generally lower than in the paint itself.

Choe et al. (2000) studied the dust generation during scraping and dry machine sanding of wood, covered with leaded paint at laboratory conditions. The tests were performed in a $24.3 \mathrm{~m}^{3}$ test room representing the size of a typical residential room. They measured particle concentrations with a Grimm model 1.108 optical particle counter, using data in the size range $0.4-20 \mu \mathrm{m}$. Immediately after sanding there was a size mode around $3 \mu \mathrm{m}$ and another at or below the lower size limit, $400 \mathrm{~nm}$. Emissions of particles from the sanding machine were not addressed. However, the motors in electrically driven sanding machines can be a prominent source of nano-sized particles. For example, Szymczak et al. (2007) reported electrical motors to be a major source of particles; especially for particles below $100 \mathrm{~nm}$ size. In Szymczak's study, a professional vacuum cleaner motor was used as the source of particles. The total number concentration produced by the motor, which was operated at full power in the test room $\left(4.2 \mathrm{~m}^{3}\right.$ with air exchange rate 0.021 per $\mathrm{m}$ ), saturated rapidly at $3.0 \times 10^{8}$ per $\mathrm{cm}^{3}$ within $15 \mathrm{~min}$ of operation.

In this study, we characterize in detail the airborne particle size distributions of the total dust, which are generated during sanding painted or lacquered surfaces. We also study the emissions of particles generated during sanding filler, which often is the last raw finish of walls and ceilings in modern buildings. The sanding particles are generated in a setup designed for simultaneous electrostatic collection of the sanding particles for subsequent physicochemical and toxicological analysis. We characterize the contribution from both the sander and the paint and discuss the results in terms of number size distribution as well as surface area and volume size distributions. This information can be used for improved assessment of the exposure risk during sanding painted surfaces, which is an important occupational and consumer activity, as well as to evaluate the appropriateness of personal protective equipments.

\section{Materials and methods}

\section{Experimental Setup and Instrumentation}

The experiment was conducted inside a $20.6 \mathrm{~m}^{3}$ human exposure chamber made with an inner wall of stainless steel and a nominal air exchange rate of $9.2 \pm 0.8$ per $\mathrm{h}$ (Lennert et al., 1997). HEPA filtering of the supply air to exposure chamber assured low total background particle concentrations $\left(<300\right.$ per $\left.\mathrm{cm}^{3}\right)$. Figure 1 shows the experimental

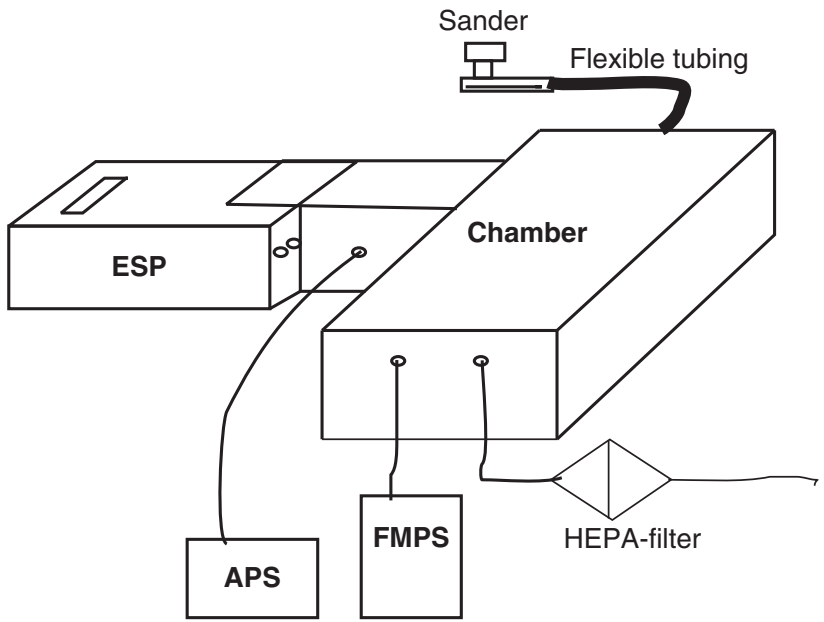

Figure 1. Schematic illustration of the measurement setup. ESP, electrostatic precipitator; APS, (Aerodynamic Particle Sizer) and FMPS, (Fast Mobility Particle Sizer).

setup, which consists of a sander unit, a sampling tube, a grounded $0.03 \mathrm{~m}^{3}$ aerosol sampling chamber in plastic, and a modified commercial electrostatic precipitator (ESP), previously characterized by Sharma et al. (2007) for particle sampling. The dust particles were sampled for completion of subsequent physicochemical analysis and toxicological tests.

The particle size distribution in the sampling chamber was measured using an APS Model 3321 (aerosol particle sizer; TSI), which measures the size distribution of particles from 0.542 to $19.81 \mu \mathrm{m}$ (aerodynamic diameter). Due to the high particle concentrations, we used a TSI diluter model 3302A with a dilution ratio of 100:1. An FMPS Model 3091 (Fast Mobility Particle Sizer; TSI), which measures the particle size distribution from 5.6 to $542 \mathrm{~nm}$ in 32 channels (mobility diameter), was used for sizing smaller particles. The APS and FMPS data were exported at a $10 \mathrm{~s}$ time resolution, which was sufficient to observe the relatively rapid changes in the aerosol spectra during the different stages of the experiments.

Sanding was performed using a commercial handheld orbital sander (Metabo Model FSR 200 Intec) with an internal fan for dust removal. Grit size 240 sanding paper was used as recommended by the paint and lacquer manufactures. This grit size is usually applied for finishing. By using this fine grit size, we also expected an enhanced production of small particles. However, the actual role of the grit size of the sanding paper is uncertain (Thorpe and Brown, 1994; Carlton et al., 2003). Carlton et al. (2003) did not observe differences in the particle size distribution using grit size 180 and 240, whereas Thorpe and Brown (1994) observed an inconsistent effect of grit size on the particle size in the dust. The downward pressure applied to the surface during the sanding may also play a role on the amount and size distribution of the generated dust. Our design did not allow to physically control this pressure. Conversely, sanding is not likely to be carried out at the same downward pressure 
in reality due to different properties of different surfaces. For harmonization, we choose a method where all the sanding experiments were performed by the same person using the same protocol (sanding procedure, movement across the plate, sensed low downward pressure, etc.) to make experiments as similar as possible.

The Metabo sander was delivered with a filter bag attached to filter exhaust air. For our purpose, the filter bag was removed and the outlet modified to connect a $60 \mathrm{~cm}$ long and $32 \mathrm{~mm}$ i.d. flexible plastic tube to lead the dust to the aerosol sampling chamber from which sampling by the APS and FMPS was performed through $10 \mathrm{~mm}$, TSI conductive silicone tubing. The ESP was attached at the side of the chamber sampling air through a $21 \mathrm{~cm}$ deep, $37 \mathrm{~cm}$ wide, and $15 \mathrm{~cm}$ high extension of the sampling chamber made in aluminum (see Figure 1).

The airflow from the sander to the sampling chamber and the flow from the chamber to ESP were measured with a Pitot tube and a micromanometer (TT 570SV; DP Measurement, UK). The volume flow to the ESP influences the cut size and collection efficiency of the ESP sampler and will be described elsewhere. The volume flow from the sander was $100 \mathrm{~m}^{3} / \mathrm{h}$ measured at the end of the tube leading dust to the sampling chamber. HEPA-filtered makeup air was supplied to the reservoir at a volume flow rate $201 / \mathrm{min}$, resulting in a $20-834.41 / \mathrm{min}$ ratio between the sample flow and the dilution air, which is less than $3 \%$ of the total sampled air. The volume flow of the sampler is $273 \mathrm{~m}^{3} / \mathrm{h}$ in standard settings as defined by Sharma et al. (2007). In this study, the pre-filter was removed and the flow was reduced to $101.2 \mathrm{~m}^{3} / \mathrm{h}$. Consequently, based on the results from Sharma et al. (2007), we can assume a collection efficiency exceeding $90 \%$ in the range between $30 \mathrm{~nm}$ and $3 \mu \mathrm{m}$.

\section{Description of the Studied Products}

The Danish paint and lacquer industry provided 13 paints, lacquers, and fillers applied on wooden plates produced by several manufacturers. G1 and G4 products were applied onto MDF plates and pines were used for acryl binder paints
(G2 and G3) and G5 lacquers were delivered on coated particle board. There was a reference plate for each product type, which did not contain any ENP, and corresponding plates where some of fillers or pigments had been replaced by materials categorized as ENPs (Table 1). These ENP materials comprised different $\mathrm{TiO}_{2}$ and $\mathrm{SiO}_{2}$ particles as well as kaolinite, carbon black, and perlite. However, some of these materials were not ENPs in the strict sense (RDI-S and maybe also kaolinite and perlite), because they were larger than $100 \mathrm{~nm}$ from their physical description and/or not engineered (Table 1). The paints included types of polyvinyl acetate and acryl. The lacquer was a UV-hard coat, and the filler was a fine-grained filler used for finishing of interior walls and ceilings before painting or mounting wallpaper, and so on. We named and grouped the products according to their applications, types, and type of ENP added (Table 1). These codes will be used throughout this paper.

\section{Measurement Procedure}

Each experiment was conducted following the same procedure. First, the ventilation system in the human exposure chamber was turned on to clean the background air while measuring the particle concentrations in the chamber by the APS and FMPS. This lasted until the background concentration was less than 300 particles per $\mathrm{cm}^{3}$ and stable. Then the instruments and the sander were connected to the sampling chamber and the size distribution in the sampling chamber was measured (Figure 2). The total particle concentration was always below 200 per $\mathrm{cm}^{3}$ inside the sampling chamber before starting the sanding experiments. Sander emissions were measured for about $1 \mathrm{~min}$ before each experiment (see Figure 2). Then the ESP was turned on and sanding of a coated plate was started. Sanding was carried out for a 1-2 min at a time until sufficient material was collected on the ESP collection plates, as assessed visually. This took 15-30 min depending on the type of product. The plates were carefully observed during the sanding process to prevent contamination from the wooden boards in the sanding dust. After sanding, the sanding and collection

Table 1. Classification, characterization, and codes of the products used for the sanding tests.

\begin{tabular}{|c|c|c|c|c|}
\hline Group & Reference & Nanomaterial & & \\
\hline $\begin{array}{l}\text { Indoor wall } \\
\text { paint (G1) }\end{array}$ & $\begin{array}{l}\text { PVA (polyvinyl } \\
\text { acetate) (G1R) }\end{array}$ & $9.8 \%$ RDI-S (rutile; $220 \mathrm{~nm}$ ) (G1A) & $\begin{array}{l}10.0 \% \mathrm{~W} 2730 \mathrm{X} \\
(\text { anatase } ;<100 \mathrm{~nm})(\mathrm{G} 1 \mathrm{~B})\end{array}$ & $\begin{array}{l}14.7 \% \text { ASP-90 } \\
\text { (kaolinite, } 200 \mathrm{~nm})(\mathrm{G} 1 \mathrm{C})\end{array}$ \\
\hline Metal/wood (G2) & Acryl binder (G2R) & $\begin{array}{l}2.5 \% \text { Flammrüss } 101 \text { (carbon black; } \\
95 \mathrm{~nm})(\mathrm{G} 2 \mathrm{~A})\end{array}$ & $10 \%$ UV titan (anatase; $17 \mathrm{~nm})(\mathrm{G} 2 \mathrm{~B})$ & \\
\hline $\begin{array}{l}\text { Outdoor wall } \\
\text { paint (G3) }\end{array}$ & Acryl binder (G3R) & $\begin{array}{l}\sim 10 \% \text { Nano-silica sol }\left(\mathrm{SiO}_{2}\right. \\
7 \mathrm{~nm})(\mathrm{G} 3 \mathrm{~A})\end{array}$ & & \\
\hline Filler (G4) & $\mathrm{CaCO}_{3}(\mathrm{G} 4 \mathrm{R})$ & $\mathrm{CaCO}_{3}+$ perlite $^{\mathrm{a}, \mathrm{b}}(\mathrm{G} 4 \mathrm{~A})$ & & \\
\hline Lacquer (G5) & UV-hard coat (G5R) & $5 \%$ Nano- $\mathrm{SiO}_{2}\left(\mathrm{SiO}_{2} ;<50 \mathrm{~nm}\right)(\mathrm{G} 5 \mathrm{~A})$ & & \\
\hline
\end{tabular}

Material data and added amounts (wet wt \%) are from the paint suppliers.

${ }^{\mathrm{a}}$ Perlite is an expanded volcanic glass formed by heating.

${ }^{\mathrm{b}}$ The added amount and composition is unknown. 


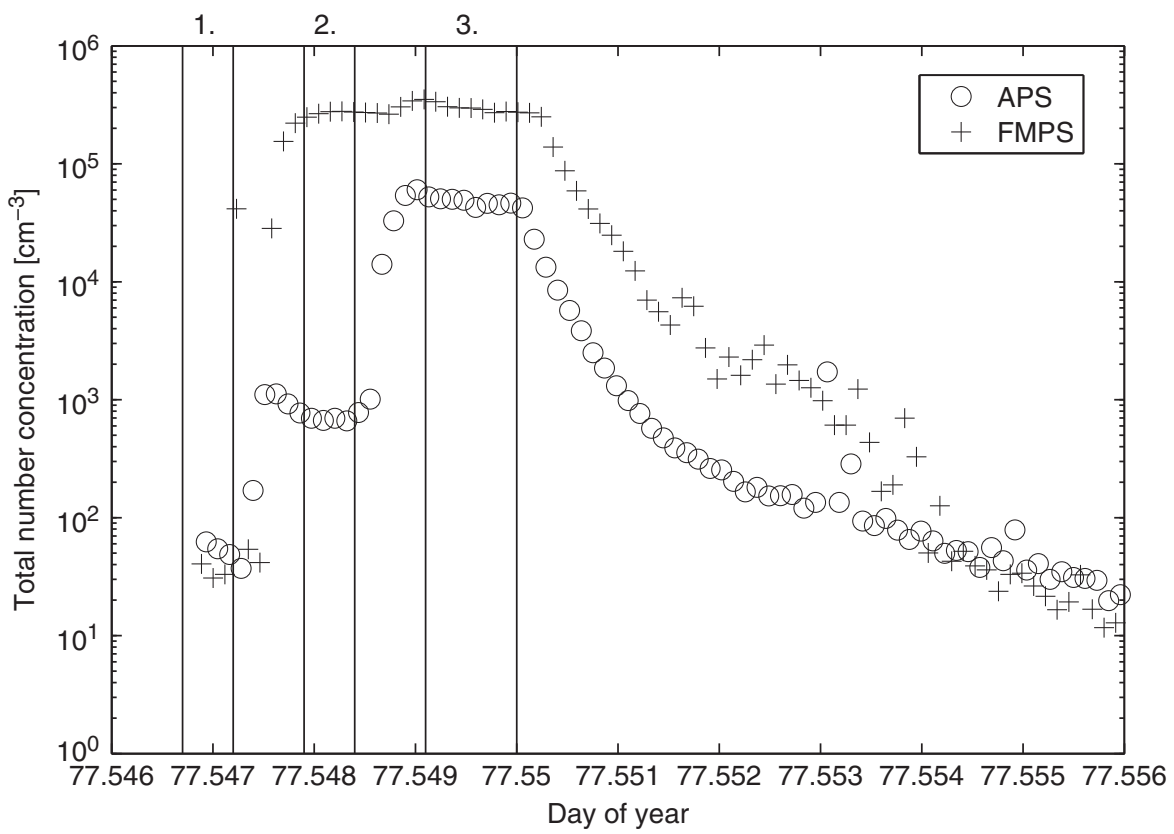

Figure 2. Evolution of total aerosol particle concentration during experiments. Numbers 1, 2, and 3 are the three phases of one experiment; background measurement, sanding machine emission measurement and measurements during sanding, respectively.

systems were dismantled and thoroughly cleaned with a vacuum cleaner.

\section{Data Analysis}

Sanding emissions were tested and analyzed once for each product. Standard deviations in all size distribution plots represent concentration deviations during the experiments. The shape of the size distribution spectra was always stable during the whole experiment for each product. To evaluate the characteristics of the measured aerosol number size distributions for each product, we fitted a multimodal lognormal distribution to the measured spectra. Fitting gave three parameters: the geometric mean diameter (GMD), the number concentration $(N)$, and the standard deviation (SD) of each mode, the fitting method is described in the paper by Mäkelä et al. (2000).

\section{Results}

\section{Particle Total Concentrations}

Figure 2 illustrates how the total number concentration evolves during a sanding experiment and defines three phases (1, background measurement; 2, measurement of sanding machine emissions; 3 , emissions from sanding the product). Table 2 presents the total number concentrations for the individual and combined FMPS and APS measurements as well as the particle number concentrations subtracted from the emissions from the sanding machine. The values are averaged over the time interval during phase 2 where the sanding machine emissions had constant concentrations and while sanding each of the coated plates (phase 3). As shown by the individual FMPS and APS measurements, the results indicate that the number of submicrometer particles always greatly exceed the number of supramicrometer particles.

On average, emissions from the sanding machine resulted in $2.75 \mathrm{E} 5$ per $\mathrm{cm}^{3}$ with an SD of $4.68 \mathrm{E} 4$ per $\mathrm{cm}^{3}$ in the aerosol collection chamber (see Table 2). Total number concentrations, including sanding machine emissions, varied between 3.39E5 (acryl binder with Flammrüss 101; G2A) and 24.7E5 per $\mathrm{cm}^{3}$ (reference lacquer; G5R) with an average of $6.39 \mathrm{E} 5 \pm 5.71 \mathrm{E} 5$ per $\mathrm{cm}^{3}(4.86 \mathrm{E} 5 \pm 1.59 \mathrm{E} 5$ per $\mathrm{cm}^{3}$ ) excluding data for G5R. The maximum value from G5R was 3.3 times higher than the second highest (G4B) and 7.2 times higher than lowest value (G2A). The high particle concentration reached during sanding of G5R is dominated by fine particles $(<100 \mathrm{~nm})$ in the FMPS measurement range. Generation of these fine particles and high number concentrations were confirmed in an additional test.

Subtracting the particle emissions from the sanding machine, the total number concentrations varied between $0.80 \mathrm{E} 5(\mathrm{G} 1 \mathrm{R})$ and $4.16 \mathrm{E} 5 \mathrm{per}^{3} \mathrm{~cm}^{3}$ (G1B), with the average being $2.10 \mathrm{E} 5 \pm 1.33 \mathrm{E} 5$ per $\mathrm{cm}^{3}$ (without the G5R results; 22.0E5). Noteworthy, sanding the three reference paints (G1R, G2R, and G3R) resulted in quite similar particle concentrations with an average of $9.87 \mathrm{E} 4 \pm 1.7 \mathrm{E} 4$ per $\mathrm{cm}^{3}$, without sanding machine emissions. Yet, the PVA-based paint appeared to result in lower dust emissions than the acryl-based paints, G2R and G3R. 
Table 2. Total number concentration averages from sanding experiments and their standard deviations in parenthesis.

\begin{tabular}{|c|c|c|c|c|c|c|}
\hline \multirow[t]{2}{*}{ Product } & \multicolumn{2}{|c|}{ FMPS $\left(\mathrm{cm}^{-3}\right)(* 1 \mathrm{E} 5)$} & \multicolumn{2}{|c|}{ APS $\left(\mathrm{cm}^{-3}\right)$} & \multirow{2}{*}{$\begin{array}{l}\text { Particle emission Product } \\
\qquad\left(\mathrm{cm}^{-3}\right)(* 1 \mathrm{E} 5)\end{array}$} & \multirow{2}{*}{$\begin{array}{c}\text { Particle emission } \\
\text { Sanding }^{\mathrm{b}}\left(\mathrm{cm}^{-3}\right)\left({ }^{*} 1 \mathrm{E} 5\right)\end{array}$} \\
\hline & Sander & Sanding & Sander(*1E2) & Sanding(*1E4) & & \\
\hline G1R & $2.60(0.21)$ & $2.94(0.27)$ & $7.51(1.34)$ & $4.66(0.33)$ & 0.80 & 3.41 \\
\hline G1A & $2.85(0.23)$ & $3.56(0.96)$ & $3.17(1.50)$ & $1.93(0.30)$ & 0.90 & 3.75 \\
\hline G1B & $3.17(0.26)$ & $5.99(0.21)$ & $1.17(0.08)$ & $13.4(0.48)$ & 4.16 & 7.33 \\
\hline G1C & $2.92(0.05)$ & $4.59(0.28)$ & $4.48(0.30)$ & $6.30(0.52)$ & 2.30 & 5.22 \\
\hline G2R & $2.41(0.07)$ & $3.51(0.23)$ & $1.48(7.45)$ & $0.40(0.09)$ & 1.14 & 3.55 \\
\hline G2A & $1.55(0.54)$ & $3.32(0.02)$ & $2.01(0.74)$ & $0.67(0.03)$ & 1.18 & 3.39 \\
\hline G2B & $3.18(0.26)$ & $4.06(0.32)$ & 8.95 (1.17) & $0.56(0.12)$ & 0.93 & 4.11 \\
\hline G3R & $2.98(0.34)$ & $3.95(0.16)$ & $2.31(0.23)$ & $0.49(0.17)$ & 1.02 & 4.00 \\
\hline G3A & $2.32(0.07)$ & $3.40(0.32)$ & $1.90(0.15)$ & $0.69(0.09)$ & 1.45 & 3.47 \\
\hline G4A & $2.95(0.05)$ & $5.64(0.61)$ & $0.95(0.13)$ & $5.99(0.47)$ & 3.29 & 6.24 \\
\hline G4B & $3.36(0.15)$ & $7.19(0.84)$ & $1.02(0.11)$ & $1.69(0.17)$ & 4.00 & 7.36 \\
\hline G5R & $2.71(0.31)$ & $24.2(5.50)$ & $1.57(0.35)$ & $5.24(0.46)$ & 22.0 & 24.7 \\
\hline G5A & $2.79(0.44)$ & $6.44(1.23)$ & $7.06(2.03)$ & $0.99(0.27)$ & 3.74 & 6.54 \\
\hline
\end{tabular}

${ }^{a}$ The particle number concentration is corrected for emissions from the sander.

${ }^{\mathrm{b}}$ The particle number concentration includes emissions from the sander.

The variations within the different product groups showed that dust emissions from G1 (PVA paint) were between $0.80 \mathrm{E} 5$ and $4.16 \mathrm{E} 5$ per $\mathrm{cm}^{3}$, with the reference paint (G1R) giving the lowest amounts and the photocatalytic $\mathrm{TiO}_{2}$-doped paint (G1B) being the highest. G1A, doped with RDI-S $\left(220 \mathrm{~nm}\right.$ size $\left.\mathrm{TiO}_{2}\right)$, had slightly higher emissions than the reference paint, whereas G1C, doped with kaolinite (ASP-90), had almost three times higher dust emissions than the reference paint.

In the acryl paint group, G2, the $17 \mathrm{~nm}$ UV-titan-doped product (G2B) had the lowest dust emissions. Sanding the carbon black-doped paint (G2A) resulted in about $20 \%$ higher particle concentrations, which was only slightly higher than the concentrations reached during sanding the reference paint. In the second acryl group, G3, the particle concentrations reached during sanding the reference paint $(\mathrm{G} 3 \mathrm{R})$ and the $7 \mathrm{~nm}$ nano-silica-sol-doped paint (G3A) are quite similar. The emission from the sanding machine was a little higher in the test of the reference paint than in the other tests. However, without the sanding machine emissions, the nanosilica-sol-doped paint do still have higher dust emissions.

Particle emissions during sanding the filler and the lacquer were generally higher as compared to emissions from the paints. Only G1B had higher emissions than G4R and G5B; these products generated approximately the same number of particles as G4A. However, the number of particles generated during sanding of G4A was still only one third of the concentrations produced during sanding of G5R.

\section{Aerosol size distribution spectra analysis}

\section{Number Size Distributions}

Analysis of the aerosol particle number size distributions showed that five size modes occur in all dust emission measurements when the sanding machine emissions are included. Hereafter, we denote the modes as the first, second, third, fourth, and fifth mode according increasing size; that is, the first mode is the smallest and the fifth mode is the largest size mode.

Group 1 (G1) Figure 3a presents aerosol size distribution measurements of $\mathrm{G} 1$ paints and corresponding results from log-normal fitting to the measured spectra can be found from Supplementary Material (Supplementary Figures S1 and S2). In Figure 3a, the average distributions are presented as pure paint dust emissions; that is, after subtracting the emissions from the sanding machine in the spectra. The average size distribution spectrum from the sanding machine is presented as background spectrum. According to Figure $3 \mathrm{a}$, the first and second modes mostly originate from the sanding machine and peak around 10 and $15 \mathrm{~nm}$, respectively. The particle concentrations in the first mode varied from $5.3 \mathrm{E} 4$ to $6.3 \mathrm{E} 4$ per $\mathrm{cm}^{3}$ and from $1.74 \mathrm{E} 5$ to $2.53 \mathrm{E} 5$ per $\mathrm{cm}^{3}$ in the second mode (Table 3 ). Addition of ENPs to the G1 paints does not have a clear effect on the size distribution spectra of the sanding dust emissions. However, the different spectra may still be influenced by different sizes and properties of the kaolinite (ASP-90), which is a clay product of platy particles, and the generally more equidimensional $\mathrm{TiO}_{2}$ nanoparticles $(220 \mathrm{~nm}$ RDI-S and W2730X with an average size $<100 \mathrm{~nm}$ ).

According to modal analysis, the largest variations in the third mode GMDs were observed with G1 emissions. This is important because the third mode is considered not to be influenced by sanding machine emissions and therefore could give an indication of whether adding ENPs affect the dust size spectra. The third-mode peaks between 130 and $180 \mathrm{~nm}$ in dust from G1R, G1A, and G1B have a clear 'shoulder' below $100 \mathrm{~nm}$, which becomes visible after deducting the 

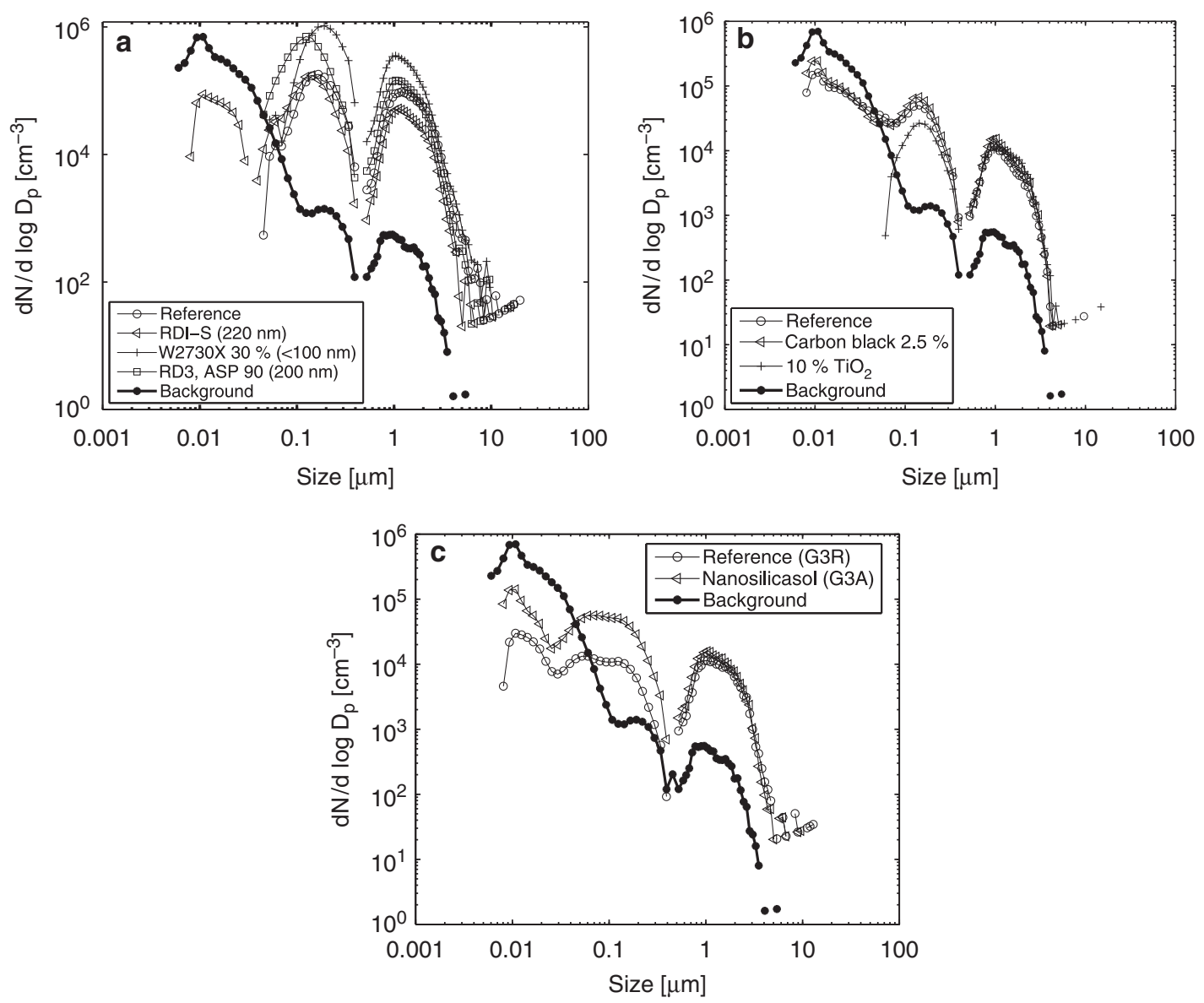

Figure 3. Measured aerosol size distributions from sander (background) and from (a) group 1, (b) group 2, and (c) group 3 paints corrected for sander emission.

Table 3. Fitting parameters obtained from fitting log-normal distributions to measured spectra.

\begin{tabular}{|c|c|c|c|c|c|c|c|c|c|c|c|c|c|c|c|}
\hline \multirow[t]{2}{*}{ Product } & \multicolumn{3}{|c|}{ Mode 1} & \multicolumn{3}{|c|}{ Mode 2} & \multicolumn{3}{|c|}{ Mode 3} & \multicolumn{3}{|c|}{ Mode 4} & \multicolumn{3}{|c|}{ Mode 5} \\
\hline & $\sigma$ & $\begin{array}{c}\text { GMD } \\
(\mathrm{nm})\end{array}$ & $\begin{array}{l}N(1 \mathrm{E} 5) \\
\left(\mathrm{cm}^{-3}\right)\end{array}$ & $\sigma$ & $\begin{array}{c}\text { GMD } \\
(\mathrm{nm})\end{array}$ & $\begin{array}{l}N(1 \mathrm{E} 5) \\
\left(\mathrm{cm}^{-3}\right)\end{array}$ & $\sigma$ & $\begin{array}{c}\text { GMD } \\
(\mu \mathrm{m})\end{array}$ & $\begin{array}{l}N(1 \mathrm{E} 5) \\
\left(\mathrm{cm}^{3}\right)\end{array}$ & $\sigma$ & $\begin{array}{c}\text { GMD } \\
(\mu \mathrm{m})\end{array}$ & $\begin{array}{l}N(1 \mathrm{E} 4) \\
\left(\mathrm{cm}^{-3}\right)\end{array}$ & $\sigma$ & $\begin{array}{c}\text { GMD } \\
(\mu \mathrm{m})\end{array}$ & $\begin{array}{l}N(1 \mathrm{E} 4) \\
\left(\mathrm{cm}^{-3}\right)\end{array}$ \\
\hline G1R & 1.15 & 10.1 & 0.53 & 1.79 & 13.8 & 1.94 & 1.46 & 0.16 & 0.70 & 1.25 & 1.06 & 2.11 & 1.34 & 1.66 & 2.22 \\
\hline G1A & 1.15 & 10.1 & 0.63 & 1.93 & 13.5 & 2.53 & 1.47 & 0.13 & 0.67 & 1.25 & 1.07 & 1.03 & 1.32 & 1.73 & 0.70 \\
\hline G1B & 1.16 & 10.2 & 0.55 & 1.74 & 15.8 & 1.88 & 1.47 & 0.18 & 3.72 & 1.25 & 1.01 & 6.57 & 1.32 & 1.57 & 4.93 \\
\hline G1C & 1.15 & 10.1 & 0.54 & 1.76 & 14.1 & 1.76 & 1.45 & 0.13 & 2.32 & 1.26 & 1.03 & 3.41 & 1.31 & 1.64 & 2.11 \\
\hline G2R & 1.15 & 10.0 & 0.70 & 2.05 & 12.6 & 3.00 & 1.48 & 0.14 & 0.21 & 1.31 & 0.99 & 0.34 & 1.32 & 1.84 & 0.11 \\
\hline G2A & 1.15 & 10.0 & 0.66 & 1.95 & 12.4 & 2.76 & 1.61 & 0.13 & 0.31 & 1.25 & 0.96 & 0.33 & 1.39 & 1.60 & 0.22 \\
\hline G2B & 1.15 & 10.0 & 0.84 & 1.92 & 12.7 & 3.51 & 1.49 & 0.16 & 0.16 & 1.27 & 0.95 & 0.24 & 1.38 & 1.61 & 0.25 \\
\hline G3R & 1.40 & 9.99 & 2.17 & 1.70 & 21.8 & 1.27 & 1.41 & 0.13 & 0.11 & 1.31 & 1.00 & 0.28 & 1.34 & 1.74 & 0.22 \\
\hline G3A & 1.40 & 9.85 & 2.03 & 1.66 & 22.7 & 0.98 & 1.63 & 0.13 & 4.94 & 1.32 & 1.02 & 0.36 & 1.34 & 1.78 & 0.27 \\
\hline G4A & 1.16 & 10.0 & 0.40 & 1.64 & 13.3 & 1.33 & 1.83 & 0.10 & 4.29 & 1.30 & 1.16 & 3.42 & 1.27 & 2.04 & 1.66 \\
\hline G4B & 1.26 & 9.79 & 1.47 & 1.59 & 14.1 & 1.08 & 1.66 & 0.05 & 4.97 & 1.36 & 1.14 & 0.90 & 1.32 & 1.93 & 0.56 \\
\hline G5R & 1.29 & 10.5 & 2.42 & 1.42 & 18.8 & 1.29 & 1.52 & 0.05 & 18.7 & 1.29 & 0.88 & 3.01 & 1.32 & 1.56 & 1.13 \\
\hline G5A & 1.42 & 9.79 & 1.66 & 1.58 & 17.4 & 0.91 & 1.54 & 0.07 & 2.45 & 1.30 & 0.89 & 0.71 & 1.23 & 1.68 & 0.17 \\
\hline
\end{tabular}

sanding machine emissions. This sub-100-nm-sized shoulder was not seen in dust from G1C with ASP-90. In G1C, the third mode is on the contrary wider than observed in sanding dust from the other $\mathrm{G} 1$ products. The modal concentration of the third mode is the highest for G1B and it also has largest GMD in $\mathrm{G} 1$ peaking in $180 \mathrm{~nm}$. 
The number concentration in the third mode shows a large variation in the sanding experiments of G1 plates $(0.67 \mathrm{E} 5$ $3.7 \mathrm{E} 5$ per $\left.\mathrm{cm}^{3}\right)$. The highest was found in $\mathrm{G} 1 \mathrm{~B}(<100 \mathrm{~nm}$ anatase) and the lowest was found in G1A (220 nm rutile). The G1B third-mode concentration is more than five times higher than that of G1A. The G1C third mode is also much higher in concentration than G1A and G1B. Hence, the apparent physical size of the ENPs added in the G1 paints does apparently not control the third mode number concentrations since G1A and G1C both contain ENPs with 200-220 nm and G1B having ENPs under $<100 \mathrm{~nm}$. However, the amount added or substituted, the material hardness and efficiency of embedding in the paints may also have a significant role.

The fourth mode occurs at almost the same size $(1.06$ (G1R), 1.07 (G1A), 1.01 (G1B), and $1.03 \mu \mathrm{m}$ (G1C)) in all G1 sanding tests. The fifth mode is observed about half micrometer above the fourth mode. GMDs of the fourth mode are between 1.57 and $1.73 \mu \mathrm{m}$ and there is less than $10 \%$ difference between the highest and lowest value. The fourth and fifth modes are the smallest in all G1 products, and it should also be noted that the shape of the fourth and fifth modes are very similar. G1B have highest concentration in both the fourth and fifth modes (6.57E4 and 4.93E4 per $\mathrm{cm}^{3}$, respectively). G1A has lowest concentrations in both of these modes (1.03E4 and $0.70 \mathrm{E} 4$ per $\mathrm{cm}^{3}$, respectively).

Group 2 (G2) G2 contains an acryl-based reference paint and two paints doped with either 95-nm-sized carbon black (Flammrüss 101) or $17 \mathrm{~nm}$ UV Titan $\left(\mathrm{TiO}_{2}\right)$. The first and second modes are assumed to be emissions from the sanding machine; however, in this case the spectra of G2R and G2B are not zero in the nanometer size range (Figure $3 \mathrm{~b}$ ). The particle concentrations in these peaks are a few thousand particles per $\mathrm{cm}^{3}$ and due to the peak shape and low particle concentrations, we assume these particles to be caused by differences in the sanding machine emissions. This may be caused by an un-noticed larger exerted pressure onto the sanding machine during the sanding. Supplementary Figure $\mathrm{S} 3$ shows the position of the five modes analyzed. Generally, only minor differences are observed in the mode positions. The third mode occurs around $150 \mathrm{~nm}$ and in G2R and G2B the modal concentrations are $\left(0.21 \mathrm{E} 5\right.$ and $\left.0.31 \mathrm{E} 5 \mathrm{~cm}^{3}\right)$ and notably higher than the concentrations in $\mathrm{G} 2 \mathrm{~B}\left(0.16 \mathrm{E} 5 \mathrm{~cm}^{3}\right)$ (Supplementary Figure S4). In all products, the fourth mode is slightly smaller than $1 \mu \mathrm{m}$. In the fifth mode, the GMD of $\mathrm{G} 2 \mathrm{R}$ is slightly larger $(1.84 \mu \mathrm{m})$ than in $\mathrm{G} 2 \mathrm{~A}(1.60 \mu \mathrm{m})$ and G2B $(1.161 \mu \mathrm{m})$. G2A and G2B have higher concentrations in the fifth mode $\left(0.22 \mathrm{E} 4\right.$ and $\left.0.25 \mathrm{E} 4 \mathrm{~cm}^{3}\right)$ than $\mathrm{G} 2 \mathrm{R}$ $\left(0.11 \mathrm{E} 4 \mathrm{~cm}^{3}\right)$, whereas $\mathrm{G} 2 \mathrm{R} \quad\left(0.34 \mathrm{E} 4 \mathrm{~cm}^{3}\right)$ and $\mathrm{G} 2 \mathrm{~A}$ $\left(0.33 \mathrm{E} 4 \mathrm{~cm}^{3}\right)$ have higher concentrations in the fourth mode than G2B $\left(0.24 \mathrm{E} 4 \mathrm{~cm}^{3}\right)$.
Group 3 (G3) G3 paints are also based on acryl and consist of the reference paint and the paint doped with 3-nmsized nano-silica sol. Figure $3 \mathrm{c}$ shows the size distribution spectra of the sanding machine emissions and spectra of the two paint products. Similar to the spectra in G2, the two spectra of the sanding dust from G3 paints show a fine nanometer-sized mode corresponding to particles from the sanding machine motor. Dust emissions in the third mode are much wider than in G1 and G2 dust emissions, suggesting a basic difference in this acryl paint as compared to the acrylbased paint in G2. Both G3 paints have the same GMD for the third mode; however, the fitting was carried out for the spectra with sander emissions and in this case this procedure has an effect on the result (see Supplementary Figure S5). This is because after deducting sanding machine emissions, the shapes of the spectra changes and reveal hidden shoulders in the spectrum. The fourth and fifth mode GMDs are almost the same indicating that adding nanoparticles did not alter the shape of the size distribution spectra. Even though the positions of the size modes were unaffected for $\mathrm{G} 3$ paints, the modal concentration in the third mode was highly affected (Supplementary Figure S6). The concentration in the third mode of G3A was almost five times higher than in G3R. For the fourth and fifth modes, the differences were smaller, G3A having approximately $20 \%$ higher concentration in both modes.

Group 4 (G4) and Group 5 (G5) G4 consists of two different types of fine fillers. The reference filler contains conventional $\mathrm{CaCO}_{3}$ (G4R) and GRA contains perlite (unspecified) replacing part of the $\mathrm{CaCO}_{3}$. Figure 4a shows the size distributions of sanding dust emissions from the G4 sanding experiments. G5 consists of two lacquer products. UV-hard coat as a reference material (G5R) and G5A contains $\mathrm{SiO}_{2}(<50 \mathrm{~nm})$. Dust emission size distribution spectra from sanding of G4 and G5 are presented in Figures $4 \mathrm{a}$ and $\mathrm{b}$.

The first and second mode sizes occur at the same position as in the studies of sanded paints. This further confirms that these two modes originate from the sanding machine motor. Compared to all sanding tests of the paints, the modal concentrations and position of the third mode in the dust generated by sanding fillers and lacquers differ significantly. The third mode is found around $50 \mathrm{~nm}$ sanding both lacquers (G5R and G5A) and light filler (G4R), but in the perlite filler (G4B), the mode peaks around $100 \mathrm{~nm}$. G5R has the highest concentration in the third mode observed in all experiments $\left(18.7 \mathrm{E} 5 \mathrm{~cm}^{3}\right)$; the second highest (G4B) has about $25 \%$ of that concentration in the third mode.

The sizes of filler modes 4 and 5 are approximately 1 and $2 \mu \mathrm{m}$, respectively, these are also the largest GMDs observed among all dust emissions measured. The corresponding lacquer modes are just below 1 and about $1.6 \mu \mathrm{m}$. A special feature in the emissions from sanding fillers is that while G4B 

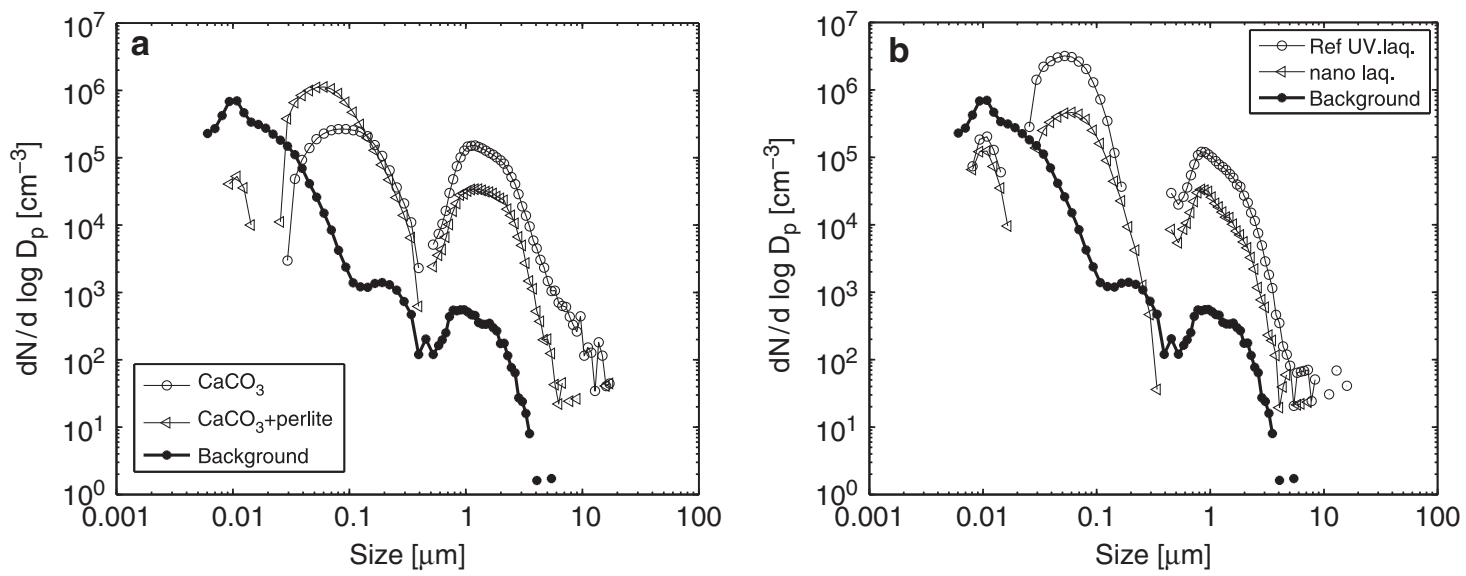

Figure 4. Measured aerosol size distributions from sander (background) as well as from group 4 fillers, and group 5 laquers corrected for sander emission are presented in a and $\mathrm{b}$, respectively.

has higher concentration in the third mode than G4A, the opposite is the case for the fourth and fifth modes. For lacquers the fourth mode has higher modal concentration than the fifth, and in G5R, the modal concentrations for these modes are higher than in G5A.

\section{Log-Normal Fitting}

In Table 3 parameters from the log-normal fittings are presented. The difference between fitted and measured total concentrations is less than $10 \%$ suggesting high reliability in the fittings. Again, fittings were carried out to spectra including sanding machine emissions and therefore the shapes of the spectra are sometimes slightly different and fits are not always perfectly comparable with size distribution spectra where sanding machine emissions are deducted.

From Table 3 fitting parameters, we get a good overview of sanding dust emissions. In this paper, we have been stating several times that first two modes are mainly from the sanding machine motor and the $10 \mathrm{~nm}$ mode may mainly be copper (Szymczak et al., 2007). This is also supported by little variation in the GMD of the first mode. The second mode has much higher variations, which indicates that there are some emissions from the paints below $20 \mathrm{~nm}$ particles. However, in the modal concentration there are large variations also in the first mode. Because the first and second modes are close to each other, the width of the mode will determine how particle concentrations are divided between the two first modes. There are two possible explanations for the concentration variations; there is paint dust below $20 \mathrm{~nm}$ or un-noticed different pressures applied to the sanding machine affects the particle number concentration associated with the operation of the electric motor.

The third mode is the first mode where emissions from the coating are apparent and is observed around $150 \mathrm{~nm}$ with all the experiments conducted with painted plates. For fillers and lacquers, the third mode was significantly smaller having a peak around $50 \mathrm{~nm}$. At the same time G4 and G5 had the highest mode 3 number concentrations. From the paints, G1B (anatase) and G1C (kaolinite) are of special interest. They had the second and third highest modal number concentrations with the highest being G3A (silica sol $<7 \mathrm{~nm}$ ). The highest concentration in the third mode was observed sanding G5R, the UV-hardened lacquer, whereas the lowest concentration was G3R metal/wood paint with acryl base.

The fourth mode GMDs were quite stable with a peak around $1 \mu \mathrm{m}$. The $\mathrm{G} 4$ fillers were the only exception, their GMDs being about $1.15 \mu \mathrm{m}$. The highest fourth mode number concentration was found in sanding test of G1B. The concentrations were almost double of the second highest found (G4A). Acryl-based paints G2 and G3 had the lowest number concentration in the fourth and fifth modes. This could indicate that dust emissions from the product in this study are also depended on base or matrix of the product.

The fifth mode GMDs are between 1.57 and $2.04 \mu \mathrm{m}$. The coarsest modal size was found in G4R. The other GMDs were typically around $1.7 \mu \mathrm{m}$. The modal concentrations varied from about $1 \mathrm{E} 3$ to $49 \mathrm{E} 3 \mathrm{~cm}^{3}$, and the highest concentration was found in G1. It seems as though G1, which has PVA as a base, had the highest number emissions of particles coarser than $1 \mu \mathrm{m}$ size.

\section{Surface and volume distribution spectra}

Table 4 presents calculated total surface areas and volumes from the measured size distribution spectra. The values are presented both including and excluding the contribution from the sanding machine emissions. Despite the high number of $10 \mathrm{~nm}$ GMD size particles, the sanding machine emissions only account for a minor fraction of the surface area and volume of the total sanding emissions. Volume and surface area spectra were both dominated by micrometersized particles, which may be relevant in risk assessment of 
Table 4. Surface areas and volumes calculated from measured size distribution spectra, assuming spherical particles and unit density.

\begin{tabular}{lcccc}
\hline Product & $\begin{array}{c}S\left(\mu \mathrm{m}^{2} \mathrm{~cm}^{3}\right) \\
\left(10^{\mathbf{6}}\right)\end{array}$ & $\begin{array}{c}S 1\left(\mu \mathrm{m}^{2} / \mathrm{cm}^{3}\right) \\
\left(10^{\mathbf{6}}\right)\end{array}$ & $\begin{array}{c}V\left(\mu \mathrm{m}^{3} / \mathrm{cm}^{3}\right) \\
\left(10^{6}\right)\end{array}$ & $\begin{array}{c}V 1\left(\mu \mathrm{m}^{3} / \mathrm{cm}^{-3}\right) \\
\left(10^{\mathbf{6}}\right)\end{array}$ \\
\hline G1R & 9.98 & 9.87 & 3.77 & 3.74 \\
G1A & 4.42 & 4.38 & 1.42 & 1.42 \\
G1B & 24.4 & 24.4 & 7.02 & 7.01 \\
G1C & 10.8 & 10.7 & 3.27 & 3.25 \\
G2R & 0.86 & 0.82 & 0.25 & 0.24 \\
G2A & 1.06 & 1.04 & 0.29 & 0.29 \\
G2B & 1.30 & 1.11 & 0.45 & 0.40 \\
G3R & 1.24 & 1.21 & 0.49 & 0.48 \\
G3A & 1.44 & 1.41 & 0.45 & 0.44 \\
G4A & 1.53 & 1.50 & 0.37 & 0.36 \\
G4B & 6.79 & 6.77 & 1.92 & 1.91 \\
G5R & 18.0 & 18.0 & 7.72 & 7.71 \\
G5A & 4.37 & 4.35 & 1.60 & 1.60 \\
\hline
\end{tabular}

$S$ and $S 1$ are calculated with sanding machine emissions, and $V$ and $V 1$ are calculated without sanding machine emissions.

dust emissions during sanding coated surfaces (Wittmaack, 2006).

Supplementary Figures S7-S11 in the Supplementary Material show the surface area spectra calculated from the number size distributions. Calculated volume size distributions are presented in the Supplementary Material (Supplementary Figures S12-S16). These figures illustrate that the surface area (two first modes) of the sanding machine motor emissions is two to three orders of magnitude smaller than surface area of $1 \mu \mathrm{m}$ particles. The corresponding differences in the volume spectra are almost four orders of magnitude.

Noteworthy, the surface area distributions from fillers and lacquers show a major difference in the size distribution spectra below $1 \mu \mathrm{m}$ as compared to that of the paint dust. The surface area spectra emphasizes that the third mode in these materials is located right between the sanding machine second and third modes. However, the fourth and fifth modes are located at the same position as found in the sanding machine and paint dust emissions. Despite very high concentrations of particles smaller than $1 \mu \mathrm{m}$, the surface and volume size distributions are still dominated by particles larger than $1 \mu \mathrm{m}$.

\section{Discussion and conclusions}

Products containing ENPs have existed on the market for more than a decade. However, the number of new ENPbased products steadily increases and they are changing from being mainly exotic to common high-volume industrial products. The paint and lacquer industry is one of the biggest potential users of ENP. The introduction of ENPs into their products results in new exposure risks to both workers in the production, application, finishing, and demolition, and consumers. To understand if and, if so, how the exposure risks from working and using these products change the characteristics of the exposure and associated risks, their emissions must be tested and compared with reference products in real user scenarios.

In this study, our aim was to investigate the particle emissions during sanding paint, lacquer, and fillers and whether substitution of some of the traditional ingredients with ENPs would change the exposure characteristics. We established a system for achieving two tasks: (1) to collect dust for physicochemical characterization and toxicological testing, and (2) to online characterize dust emission size distributions. The system was not tested experimentally with respect to quantifying the different losses and error sources, but sampling losses in the tubes between the sanding machine and sampling chamber were estimated theoretically. For particles smaller than $10 \mathrm{~nm}$, the diffusion losses were only $3 \%$ and for a $5 \mu \mathrm{m}$ particle the inertial loss was less than $2 \%$ (Baron and Willeke, 2001). Chamber losses are unknown. Different sanding papers might also cause different particle sizes and numbers in the emissions. In our study grit size 240 was chosen. We assumed that the fine paper would produce smaller particles. Pressure between the sanding machine and the painted surface might also influence emissions.

All the measured spectra have a minimum between the APS and FMPS measurement range. It is unclear whether this minimum is real or an instrumental artefact. Similar observations have been made in measurements of other types of airborne particles (Jensen et al., 2009). Part of the explanation is that the APS and FMPS do not measure the same property of the aerosol. The APS measures the aerodynamic diameter, which varies with particle density. The FMPS measures the electrical mobility and charge of the particles after equilibration with electrons in the charger unit of the instrument. The electrical mobility size of nano-size particles depends primarily on particle morphology (primary shape and agglomerate structure). In this study, we used the standard measurement strategy conditions assuming spherical particles with a density of $1 \mathrm{~g} / \mathrm{cm}^{3}$. Combination of these two types of measurements require considerations about the influence of particle densities, and in some cases also particle morphology, on the measured particle size.

The sander emissions dominate in the sub- $50 \mathrm{~nm}$ particle emissions. The concentration of particles in the first mode ( $\sim 10 \mathrm{~nm}$ GMD) and second mode ( $\sim 13-23 \mathrm{~nm}$ GMD) may depend on the pressure applied to the sander during operation. Some materials were more difficult to sand than others; that is, had a lower friction with the sanding paper. It is unclear how much the sanding machine emissions contribute in the bigger size classes. A significant fraction of the nano-size particles generated by the sanding machine may agglomerate and attach to coarser particles from the test materials and in that way cannot be detected and quantified by the APS and FMPS. The corresponding problem is that nano-size particles and free ENPs that may be released from the test materials can be hidden in the high number of 
sanding machine emission particles and undergo similar agglomerations and attachment onto coarser particles as discussed for the sanding machine particles. However, it is assumed that the sanding dust particles mainly consist of product fragments with embedded or attached ENPs. We are able to study this later by further analysis by, for example, electron microscopy.

The total particle concentrations varied significantly between the studied products. There is no simple explanation with respect to the effect of adding nanomaterials to the products or differences in the emissions between the primary products, for example, PVA or acryl paint. There was a difference in how easily dust was generated from the plates while sanding between G1, which is a PVA-based product, and $\mathrm{G} 2$ and G3, which are acryl-based products. G1 was easier to sand. However, when comparing total concentrations from Table 2, G1R has lower dust emissions than G2R. With respect to the total number concentrations, lacquer clearly resulted in the highest release of particles, which we confirmed with repeated measurements. This indicates that the harder the paint and lacquer product is, the higher the number of emitted particles may be. Naturally, this relation cannot be extended to the fillers, where sanding resulted in a very high number of particles during sanding. In addition, detectable influence on the emissions also depends on the amount of ENPs added to the test products. In this study, these concentrations varied between 2.5 and $14.7 \mathrm{wt} \%$ of the wet product. The material characteristics of the different products finally control the potential of particle generation during such processes.

From the size distribution analysis, we found five size modes, which occurred around the same sizes independent of the type of product. However, density and structure of the particles may differ and therefore the true physical sizes of the fourth and fifth modes may differ from the values reported here. Adding ENP seems not to have any clear connection to emission size distribution or total concentrations.

The measured dust emissions can be considered as worstcase scenarios, because they include measurement of the total emissions and are measured directly after the sanding machine. Normally, the sander would at least be equipped with a bag filter attached to the sanding machine and professionals would usually have a vacuum cleaner connected to the sanding device. However, the aim of this study was to investigate if ENPs alter dust emissions from these materials. Source strength experiments are conducted later to study real exposure scenarios.

Besides the use of different sanding machines, the grain size in the sanding paper may also influence the size distribution and number of particles emitted during sanding. Carlton et al. (2003) tested a pneumatic, random orbital type sander in a glove box during sanding of aluminum panels coated with aircraft epoxy primer and polyurethane paint, using grit size 180 and 240. No difference was found in inhalable dust generation between grit size 180 and 240, but there was no analysis of the particle size distribution and number of particles emitted.

In conclusion, this study shows great variability in the number of particles, which can be emitted from surface coatings (paints, lacquers, and fillers). In respect of particle number concentrations, fine particles dominate the emissions and the motor from the sanding machine is the dominant source of particles smaller than $100 \mathrm{~nm}$. By mass and surface area, all emissions are dominated by size modes above $1 \mu \mathrm{m}$. Addition of ENPs may alter the number of particles emitted from sanding the materials, but the size distributions of the dusts are not severely affected. In addition, it is unclear whether ENPs reduce or increase the exposure risk of dust particles during sanding the products tested in this study. This may be due to the presence of too many variables: different product types, different ENPs added in different concentrations $(2.5-14.7 \mathrm{wt} \%$ of the wet paint). The material characteristics of the different products appear to have a major role on the potential of particle generation during sanding.

\section{Acknowledgements}

This work was funded by The Danish Working Environment Research Fund (Nanokem, Grant No. 20060068816). We thank our technician Signe Hjortkjær Nielsen for her assistance and Danish Paint and Lacquer Industry for providing us the coated plates.

\section{Conflict of interest}

The authors declare no conflict of interest.

\section{References}

Balbus M., Florini K., Denison R.A., and Walsh S.A. Protecting workers and environment: an environmental NGO's perspective on nanotechnology. J Nanopart Res 2006: 9: 11-22.

Baron P.A., and Willeke K. Aerosol Measurement: Principles, Techniques and Applications. John Wiley \& Sons, Inc. Hoboken, New Jersey, 2001.

Brouwer D., van Duuren-Stuurman B., Berges M., Jankowska E., Bard D., and Mark D. From workplace air measurement results toward estimates of exposure? Development of a strategy to assess exposure to manufactured nano-objects. J Nanopart Res 2009: 11(8): 1867-1881.

Carlton G.N., Patel K.B., Johnson D.L., and Hall T.A. The effectiveness of handheld ventilated sanders in reducing inhalable dust concentrations. Appl Occup Environ Hyg 2003: 18: 51-56.

Choe K.T., Trunov M., Grinshpun S.A., Willeke K., Harney J., Trakumas S., and Mainelis G., et al. Particle settling after lead-based paint abatement work and clearance waiting period. Am Ind Hyg Assoc J 2000: 61: 798-807.

Donaldson K., Stone V., Gilmour P.S., Brown D.M., and MacNee W. Ultrafine particles: mechanisms of lung injury. Philos Trans $R$ Soc Lond A 2000: 358: 2741-2749.

Jensen K.A., Koponen I.K., Clausen P.A., and Schneider T. Dustiness behaviour of loose and compacted Bentonite and organoclay powders: what is the difference in exposure risk? J Nanopart Res 2009: 11(1): 133-146. 
Lennert A., Nielsen F., and Breum N.O. Evaluation of evaporation and concentration distribution models and a test chamber study. Am Occup Hyg 1997: 41(6): 625-641.

Mäkelä J., Koponen I.K., Aalto P., and Kulmala M. One-year data of submicron size modes of tropospheric background aerosol in Southern Finland. Aerosol Sci 2000: 31(5): 595-611.

Maynard A.D., Baron P.A., and Foley M. Exposure to carbon nanotube material: aerosol release during the handling of unrefined single-walled carbon nanotube material. J Toxicol Environ Health A 2004: 67: 87-107.

Oberdorster G., Oberdorster E., and Oberdorster J. Nanotoxicology: an emerging discipline evolving studies of ultrafine particles. Environ Health Perspect 1995: 113: 823-839.

Oberdorster G., Stone V., and Donaldson K. Toxicology of nanoparticles: a historical perspective. Nanotoxicology 2007: 1: 2-25.

Rossi E.M., Pylkkänen L., Koivisto A.J., Vippola M., Jensen K.A., and Sirola K., et al. Airway exposure to silica coated $\mathrm{TiO} 2$ nanoparticles induces pulmonary neutrophilia in mice. Toxicol Sci 2010: 113: 422-433.

Scholz P.F., Materna B.L., Harrington D., and Uratsu C. Residential and commercial painters' exposure to lead during surface preparation. Am Ind Hyg Assoc J 2002: 63: 22-28.

Sharma A.K., Wallin H., and Jensen K.A. High volume electrostatic field-sampler for collection of fine particle bulk samples. Atmos Environ 2007: 41: 369-381.
Szymczak W., Menzel N., and Keck L. Emission of ultrafine copper particles by universal motors controlled by phase angle modulation. J Aerosol Sci 2007: 38: $520-531$.

Thorpe A., and Brown R.C. Measurements of the effectiveness of dust extraction systems of hand sanders used on wood. Ann Occup Hyg 1994: 38: 279-302.

Wallace W.E., Keane M.J., Murray D.K., Chisholm W.P., Maynard A.D., and Ong T.-M. Phospholipid lung surfactant and nanoparticle surface toxicity: lessons from diesel soots and silicate dusts. J Nanopart Res 2006: 9: 23-38.

Warheit D.B., Webba T.R., Reeda K.L., Frerichsb S., and Sayesa C.M. Pulmonary toxicity study in rats with three forms of ultrafine- $\mathrm{TiO}_{2}$ particles: differential responses related to surface properties. Toxicology 2006: 230: 90-104

Wittmaack K. In search of the most relevant parameter for quantifying lung inflammatory response to nanoparticle exposure: particle number, surface area or what? Environ Health Perspect 2006: 115: 2.

This work is licensed under the Creative Commons Attribution-NonCommercial-No Derivative Works 3.0 Unported License. To view a copy of this license, visit http:// creativecommons.org/licenses/by-nc-nd/3.0/

Supplementary Information accompanies the paper on the Journal of Exposure Science and Environmental Epidemiology website (http://www.nature.com/jes) 